International Journal of Computer Networks \& Communications (IJCNC) Vol.3, No.6, November 2011

\title{
RWP MOBILITY MOdEL BASED PERFORMANCE EVALUATION OF OLSR AND LAR1 ROUTING PROTOCOLS IN MANET
}

\author{
Ashish K. Maurya ${ }^{1}$, Ashish Kumar ${ }^{2}$ and Dinesh Singh ${ }^{3}$ \\ 1,2,3 Department of Electronics \& Computer Engineering \\ Indian Institute of Technology Roorkee \\ Roorkee, India \\ ${ }^{1}$ er.ashishmaurya@gmail.com, ${ }^{2}$ luck.ashish@gmail.com, \\ ${ }^{3}$ devverma.itegmail. com
}

\begin{abstract}
Mobile Ad hoc NETwork (MANET) is a collection of mobile nodes that are arbitrarily located such that the interconnections between nodes are dynamically changing. In MANET, mobile nodes form a temporary network without using any kind of existing network infrastructure or centralized administration. A routing protocol is used to find routes between mobile nodes to facilitate communication within the network. Route should be discovered and maintained with a minimum of overhead and bandwidth consumption. A wide range of routing protocols for MANETs has been proposed by researchers to overcome the limitations of wired routing protocols. This paper evaluated performance of proactive routing protocol and reactive routing protocol in variable pause time and variable number of nodes. We have used Optimized Link State Routing (OLSR) protocol as proactive routing protocol and Location-Aided Routing Scheme 1 (LAR1) protocol as reactive routing protocol. We have used RWP (random waypoint) mobility model and performed simulations by using QualNet version 5.0 Simulator from Scalable Networks. Performance of OLSR and LAR1 is evaluated based on Average end to end delay, Packet delivery ratio, Throughput and Average Jitter.
\end{abstract}

\section{KEYWORDS}

MANET, OLSR, LAR1, Random Waypoint mobility model, QualNet version 5.0

\section{INTRODUCTION}

Mobile Ad Hoc Networks are the self-organizing and self-configuring wireless networks which do not rely on a fixed infrastructure and have the capability of rapid deployment in response to application needs. Nodes of these networks function as routers which discover and maintain routes to other nodes in the network. Initially, Ad-hoc networks were mainly used for military applications. Since then, they have become increasingly more popular within the computing industry. Applications include casual conferences, meetings, virtual classrooms, emergency search-and-rescue operations, disaster relief operations, automated battlefield and operations in environments where construction of infrastructure is difficult or expensive. In MANETs, due to lack of centralized entity and the mobile nature of nodes, network topology changes frequently and unpredictably. Hence, the routing protocols for ad hoc wireless networks have to adapt quickly to the frequent and unpredictable changes of topology. [2]. In MANET, there are mainly three types of unicast routing protocols: proactive routing protocols, reactive routing 
International Journal of Computer Networks \& Communications (IJCNC) Vol.3, No.6, November 2011 protocols and hybrid routing protocols. There are many proactive routing protocols available for Ad-hoc networks such as DSDV, OLSR, FSR, GSR, CGSR and IARP etc. There are also a variety of reactive routing protocols such as AODV, DSR, LAR1, DYMO and IERP etc. ZRP and TORA are hybrid routing protocols. In this paper we'll study two routing protocols: OLSR and LAR1 and evaluate the performance of these two routing protocols as a function of pause time and number of nodes.

\subsection{OLSR}

Optimized Link State Routing (OLSR) [3], [4] protocol is a table-driven proactive routing protocol for wireless mobile ad hoc networks. This protocol optimizes the flooding process and reduces the control message overheads by marking subset of neighbors as multi-point relays (MPRs). In OLSR, each node periodically broadcasts two types of messages: HELLO messages and Topology Control (TC) messages. A HELLO message contains two lists in which one list includes the addresses of the neighbors to which there exists a valid bi-directional link and the other list includes the addresses of the neighbors from which control traffic has been heard but bidirectional links are not confirmed. Upon receiving HELLO message, a node examines list of addresses, if its own address is in the list, it is confirmed that bidirectional communication has been established with the sender. HELLO messages also allow each node to maintain information describing link between neighbor node and nodes those are two-hop away. The set of nodes among the one-hop neighbors with a bi-directional link are chosen as multipoint relays (MPRs). Only these nodes forward topological information about the network [8]. On the reception of HELLO messages, each node maintains a neighbor table which contains one-hop neighbor information, their link status information and a list of two hop neighbors. Each node also maintains a set of its neighbors which are called the MPR Selectors of the node. When these selectors send a broadcast packet, only its MPR nodes among its entire neighbors forward the packet. The MPR nodes periodically broadcast its selector list throughout the network. The smaller set of multipoint relay provides more optimal routes. The path to the destination consists of a sequence of hops through the multipoint relays from source to destination. A TC message contains the list of neighbors who have selected the sender node as a multipoint relay and is used to diffuse topological information to the entire network. Based on the information contained in the neighbor table and the TC message, each node maintains a routing table which includes destination address, next-hop address, and number of hops to the destination [4], [14]. OLSR routing mechanism is shown in figure 1.

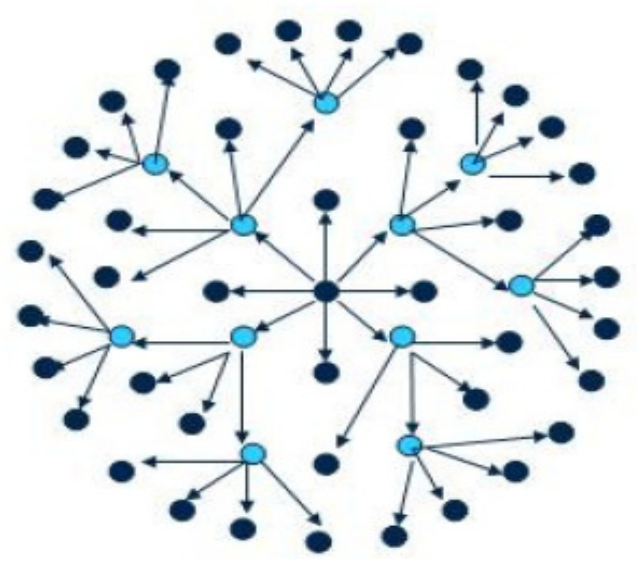

retransmitting

nodes or multipoint relays

Figure 1. OLSR Routing Mechanism 


\subsection{LAR1}

The Location-Aided routing protocol (LAR) [5] is a reactive on-demand source routing protocol that uses the location information of the mobile nodes. Location information about nodes is obtained by using Global Positioning System (GPS). LAR is an improvement over DSR in terms of route request packet flooding. In LAR, location information of mobile nodes is used to flood a route request packet only in a forwarding zone called request zone instead entire ad-hoc network. This request zone is determined by location information at destination.

\subsubsection{Expected Zone}

Suppose, source node (S) knows that the destination node (D) was at location $\mathrm{L}$ at time $\mathrm{t}_{0}$ and current time is $t_{1}$, expected zone of node $D$ from the viewpoint of node $S$ is the region that node $\mathrm{S}$ expects to contain node $\mathrm{D}$ at time $t_{1}$ based on the knowledge that node $\mathrm{D}$ was at location $\mathrm{L}$ at time $t_{0}$. The expected zone is only an estimate by $\mathrm{S}$ to determine possible locations of D [5].

\subsubsection{Request Zone}

Node $\mathrm{S}$ defines a request zone for the route request packet forwarding. An intermediate node will forward route request packet only, if it belongs to request zone. The request zone includes expected zone and other surrounding zone around the request zone. LAR defines two different types of request zones [5]: LAR Scheme 1 (LAR1) and LAR Scheme 2 (LAR2) [5]. LAR1 is used in this paper and routing mechanism of LAR1 is shown in figure 2.

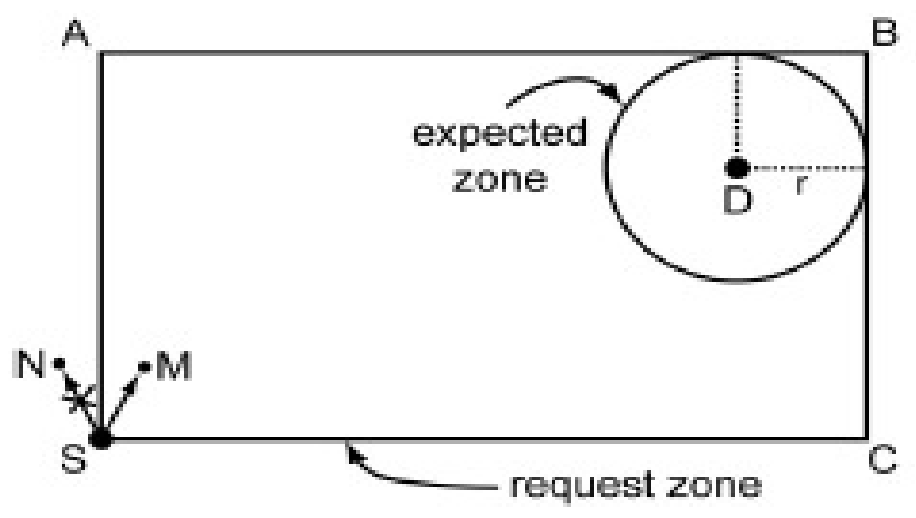

Figure 2. LAR Scheme 1 (LAR1) Routing Mechanism [6]

In LAR1, request zone is rectangular in shape. Once source knows that destination node was at location $\left(\mathrm{X}_{0}, \mathrm{Y}_{0}\right)$ at time $\mathrm{t}_{0}$, expected zone at time $\mathrm{t}_{1}$ defined as a circle with radius $\mathrm{R}=\mathrm{v}\left(\mathrm{t}_{1}-\mathrm{t}_{0}\right)$ centered at location $\left(\mathrm{x}_{0}, \mathrm{y}_{0}\right)$ where $\mathrm{v}$ is the average speed with which destination can move. The request zone is now defined as the smallest rectangle that includes current source location and expected zone such that the sides of the rectangle are parallel to the $\mathrm{X}$ and $\mathrm{Y}$ axes. To route a packet, source node $S$ determines the four corners of the rectangular request zone and includes these coordinates in the route request packet when initiating the route discovery process. The neighboring nodes which are inside the request zone only forward the route request packet further and other nodes just drop the packet. Once destination node receives route request packet, it sends backs a route reply packet with its current location, average speed and time. Source node $\mathrm{S}$ is going to use this information for a route discovery in the future [6], [15]. 
International Journal of Computer Networks \& Communications (IJCNC) Vol.3, No.6, November 2011

\section{SiMUlation ENVIRONMENT}

\subsection{RWP (Random Waypoint) Mobility Model}

The Random waypoint model is a random-based mobility model designed to describe the movement pattern of mobile users, and how their location, velocity and acceleration change over time. In this model, the node selects a random position, moves towards it in a straight line at a constant speed that is randomly selected from a range, and pauses at that destination. The node repeats this, throughout the simulation [9].

We have performed simulations on QualNet 5.0 simulator [1] and performance of OLSR and LAR1 routing protocols are evaluated in two scenarios: (1) Scenario A and (2) Scenario B. In scenario A, protocols are compared as a function of pause time and in scenario $\mathrm{B}$, the comparison is made as a function of number of nodes. Snapshot of a network in QualNet5.0 simulator is shown in figure 3 .

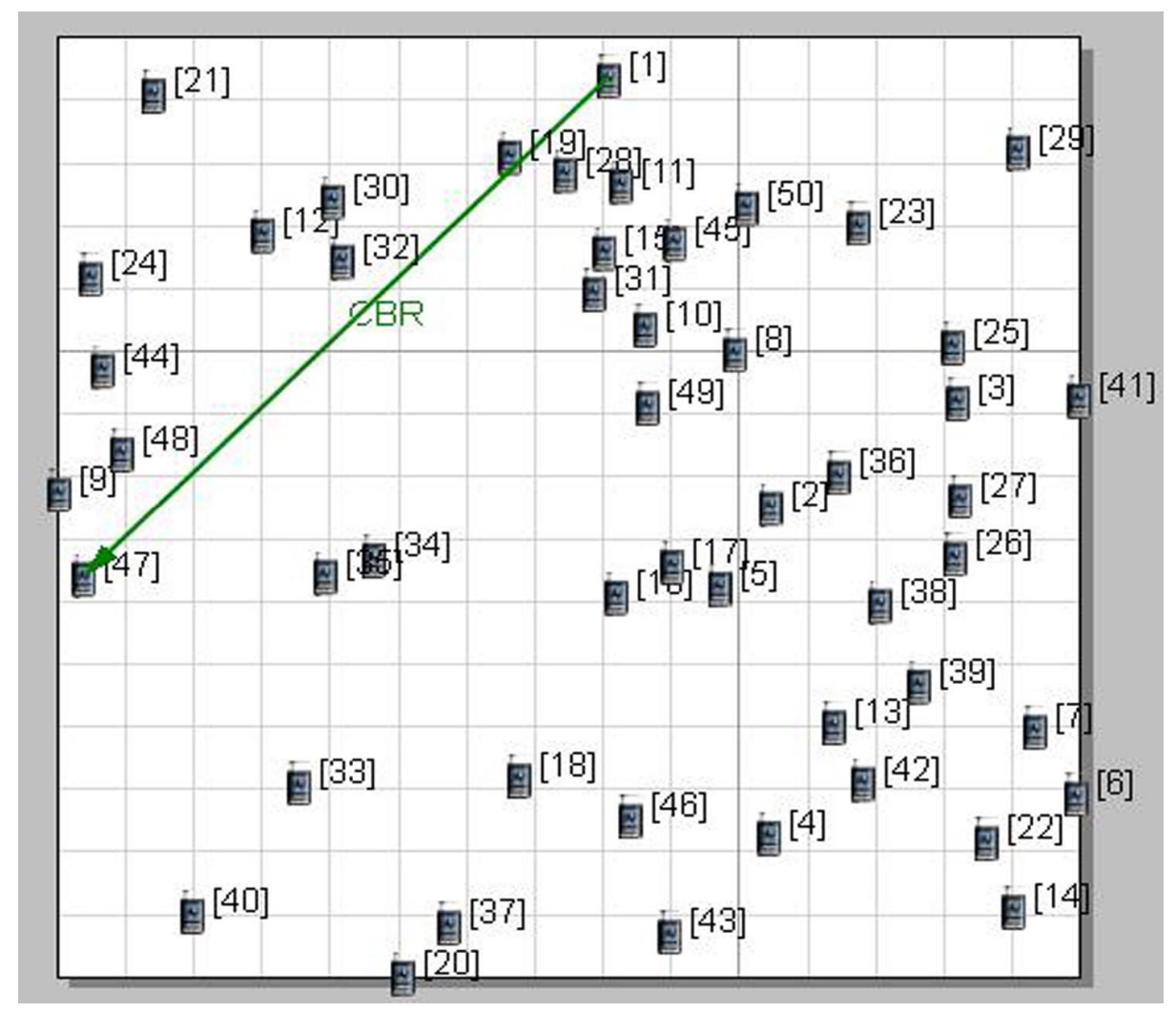

Figure 3. Snapshot of network in QualNet5.0 Simulator

For both scenarios, we have taken $1500 \mathrm{~m}$ X $1500 \mathrm{~m}$ dimension of space to perform the simulations and nodes are placed randomly on the space. In scenario A, the number of nodes is taken as 50 and simulations are performed for different pause times as 20 seconds, 40 seconds, 60 seconds, 80 seconds and 100 seconds. In scenario B, the pause time is taken as 30 seconds and simulations are performed for different number of nodes as 20 nodes, 40 nodes, 60 nodes, 80 nodes and 100 nodes. For both scenarios CBR (Constant Bit Rate) is used as a traffic source and RWP (random waypoint) as a mobility model. Minimum velocity of nodes is taken as $0 \mathrm{~m} / \mathrm{s}$ 
International Journal of Computer Networks \& Communications (IJCNC) Vol.3, No.6, November 2011 and maximum velocity of nodes is taken as $10 \mathrm{~m} / \mathrm{s}$. We have performed the simulation for 300 seconds. The simulation parameters are summarized in table 1 and table 2 for scenario A and scenario $\mathrm{B}$ respectively.

Table 1. Simulation parameters for scenario A

\begin{tabular}{|l|l|}
\hline Simulation Parameters & Values \\
\hline Dimension of space & $1500 \mathrm{~m}$ X $1500 \mathrm{~m}$ \\
\hline No. of nodes & 50 \\
\hline Minimum velocity (v min) & $0 \mathrm{~m} / \mathrm{s}$ \\
\hline Maximum velocity (v max) & $10 \mathrm{~m} / \mathrm{s}$ \\
\hline Simulation Time & $300 \mathrm{sec}$ \\
\hline Traffic Sources & CBR \\
\hline Item size & 512 bytes \\
\hline Source data pattern & 4 packets/sec \\
\hline Node Placement Strategy & Random \\
\hline Mobility Model & Random Waypoint \\
\hline Pause time & $20 \mathrm{~s}, 40 \mathrm{~s}, 60 \mathrm{~s}, 80 \mathrm{~s}, 100 \mathrm{~s}$ \\
\hline
\end{tabular}

Table 2. Simulation parameters for scenario B

\begin{tabular}{|l|l|}
\hline Simulation Parameters & Values \\
\hline Dimension of space & $1500 \mathrm{~m}$ X $1500 \mathrm{~m}$ \\
\hline No. of nodes & $20,40,60,80,100$ \\
\hline Minimum velocity (v min) & $0 \mathrm{~m} / \mathrm{s}$ \\
\hline Maximum velocity (v max) & $10 \mathrm{~m} / \mathrm{s}$ \\
\hline Simulation Time & $300 \mathrm{sec}$ \\
\hline Traffic Sources & CBR \\
\hline Item size & 512 bytes \\
\hline Source data pattern & 4 packets/sec \\
\hline Node Placement Strategy & Random \\
\hline Mobility Model & Random Waypoint \\
\hline Pause time & 30 sec \\
\hline
\end{tabular}




\section{Performance Evaluation}

To evaluate the performance of OLSR and LAR1 routing protocols, four different quantitative metrics are used. Those are average end to end delay, packet delivery ratio, throughput and average Jitter.

\subsection{Average End to End Delay}

End-to-end delay indicates how long a packet takes to travel from the CBR source to the application layer of the destination [10]. This includes all possible delays caused by buffering during route discovery latency, queuing at the interface queue, retransmission delays at the MAC layer, propagation and transfer times. The average delay from the source to the destination's application layer is shown in figure 4 and figure 5 for scenario A and scenario B respectively. According to our simulation results, OLSR demonstrates lower delay than LAR1 for both scenarios due to their operation which is table driven in nature. The presence of routing information in advance leads to lower average end-to-end delay. OLSR also optimizes the flooding process and reduces the control message overheads by marking subset of neighbors as multi-point relays

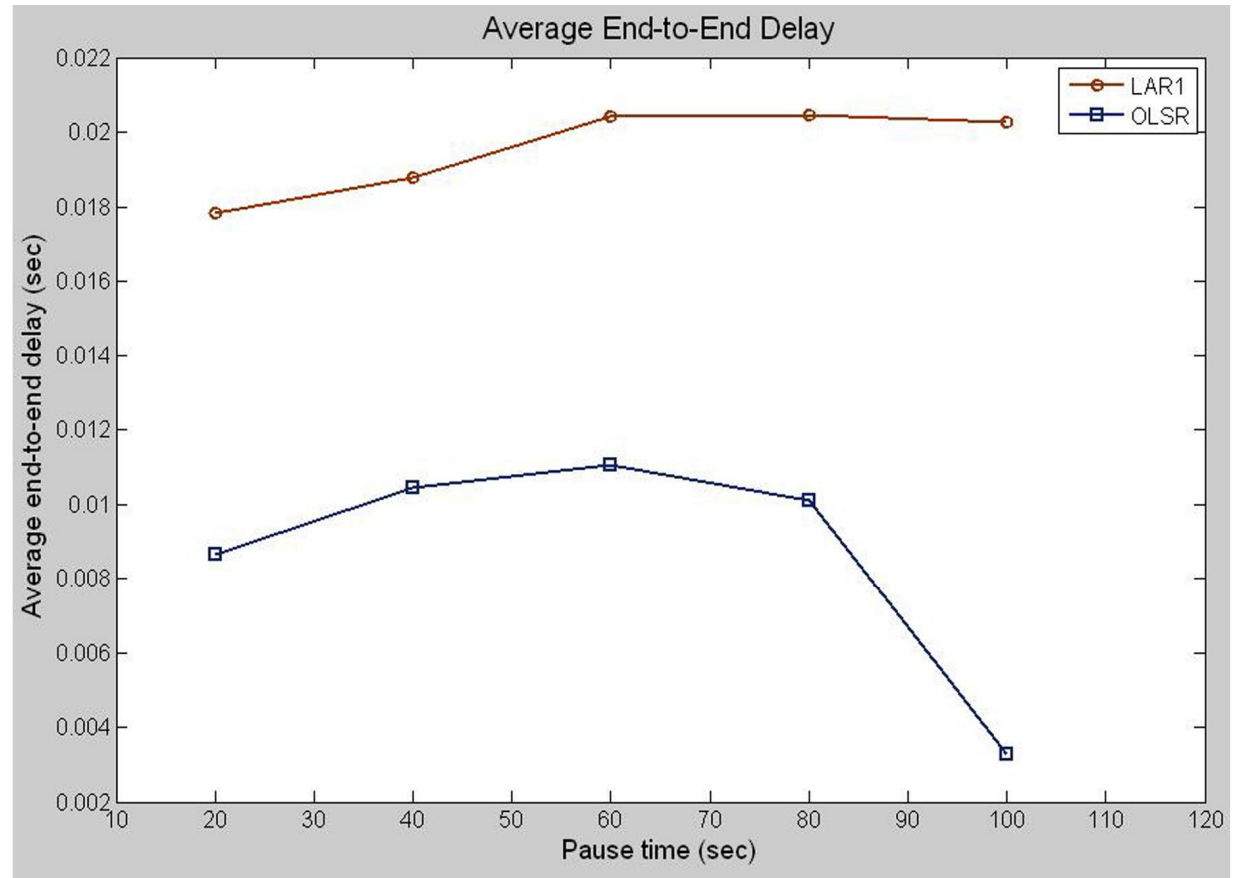

Figure 4. Average end-to-end delay for 50 nodes 
International Journal of Computer Networks \& Communications (IJCNC) Vol.3, No.6, November 2011

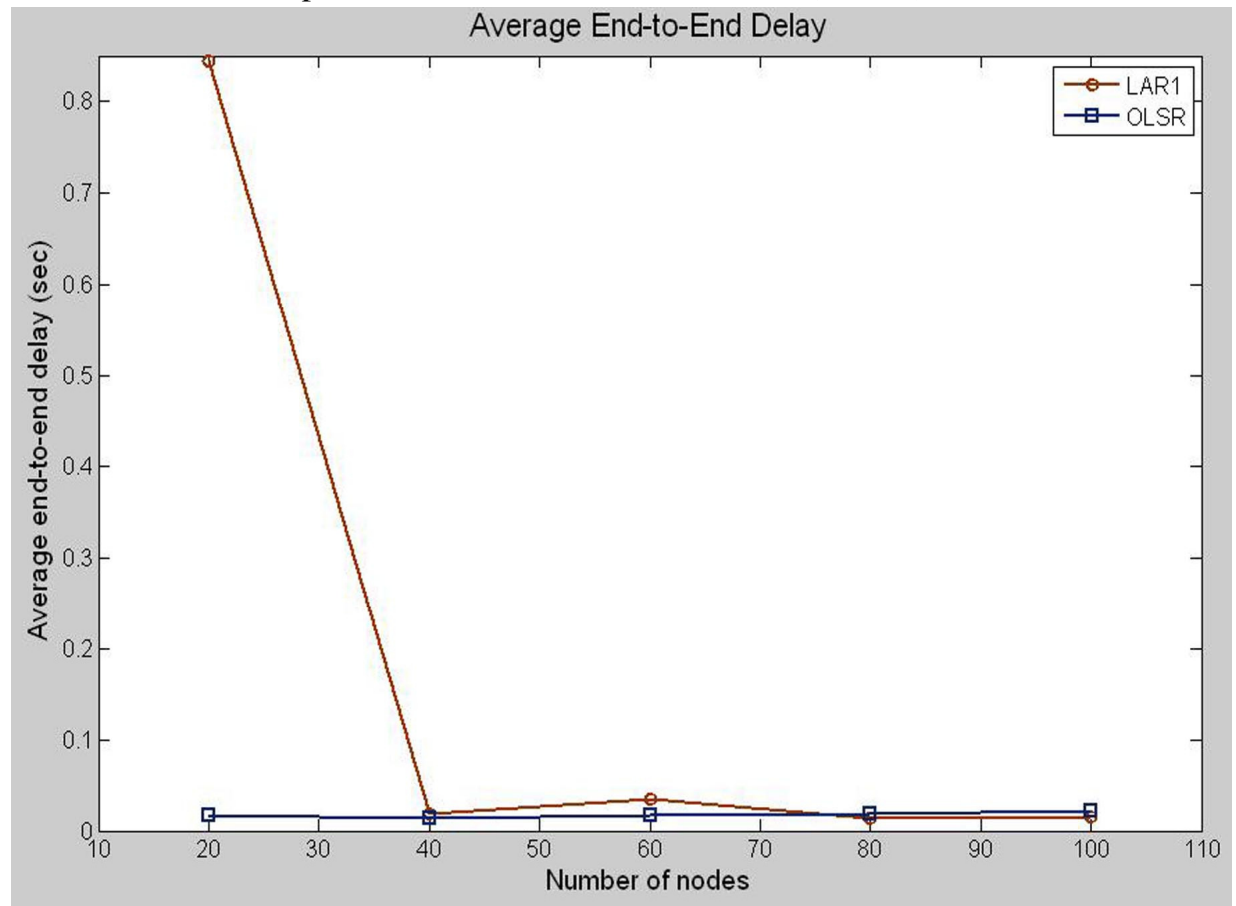

Figure 5. Average end-to-end delay for pause time $30 \mathrm{sec}$

\subsection{Packet Delivery Ratio}

Packet delivery ratio (PDR) is the fraction of packets sent by the application that are received by the receivers and it is calculated by dividing the number of packets received by the destination through the number of packets originated by the application layer of the source. For a correct routing protocol, it should be better [11]. The packet delivery ratio is shown in figure 6 and figure 7 for scenario A and scenario B respectively. According to our simulation results, LAR1 performs better than OLSR for both scenarios. In scenario A, LAR1 delivers more than 92 percent of all CBR packets whereas OLSR delivers less than 50 percent of data packets. In scenario B, initially; when node density is very less LAR1 delivers only 70 percent of CBR packets and OLSR delivers less than 30 percent of CBR packets but when node density increases, LAR1 delivers more than 90 percent of all CBR packets and OLSR delivers more than 50 percent of all data packets. 
International Journal of Computer Networks \& Communications (IJCNC) Vol.3, No.6, November 2011

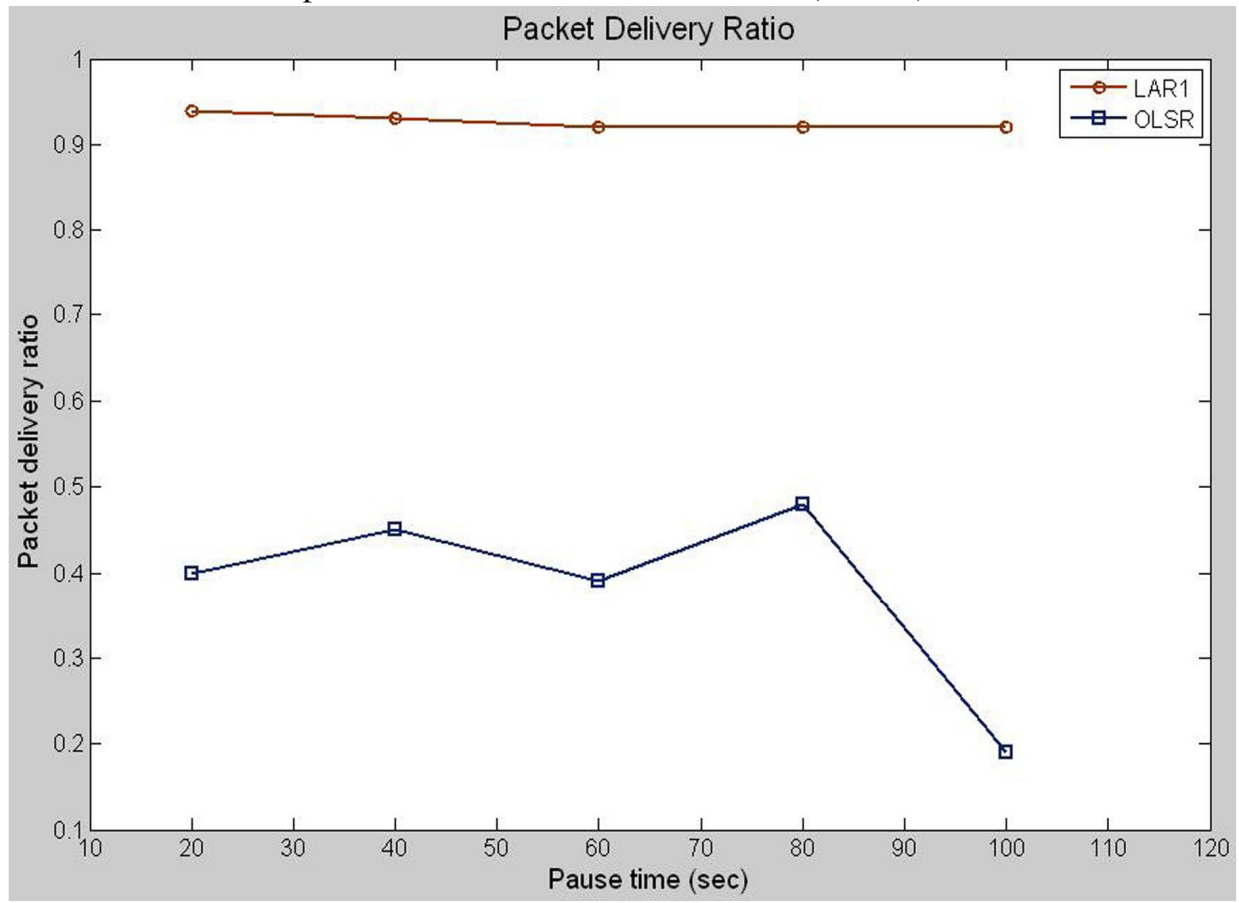

Figure 6. Packet delivery ratio for 50 nodes

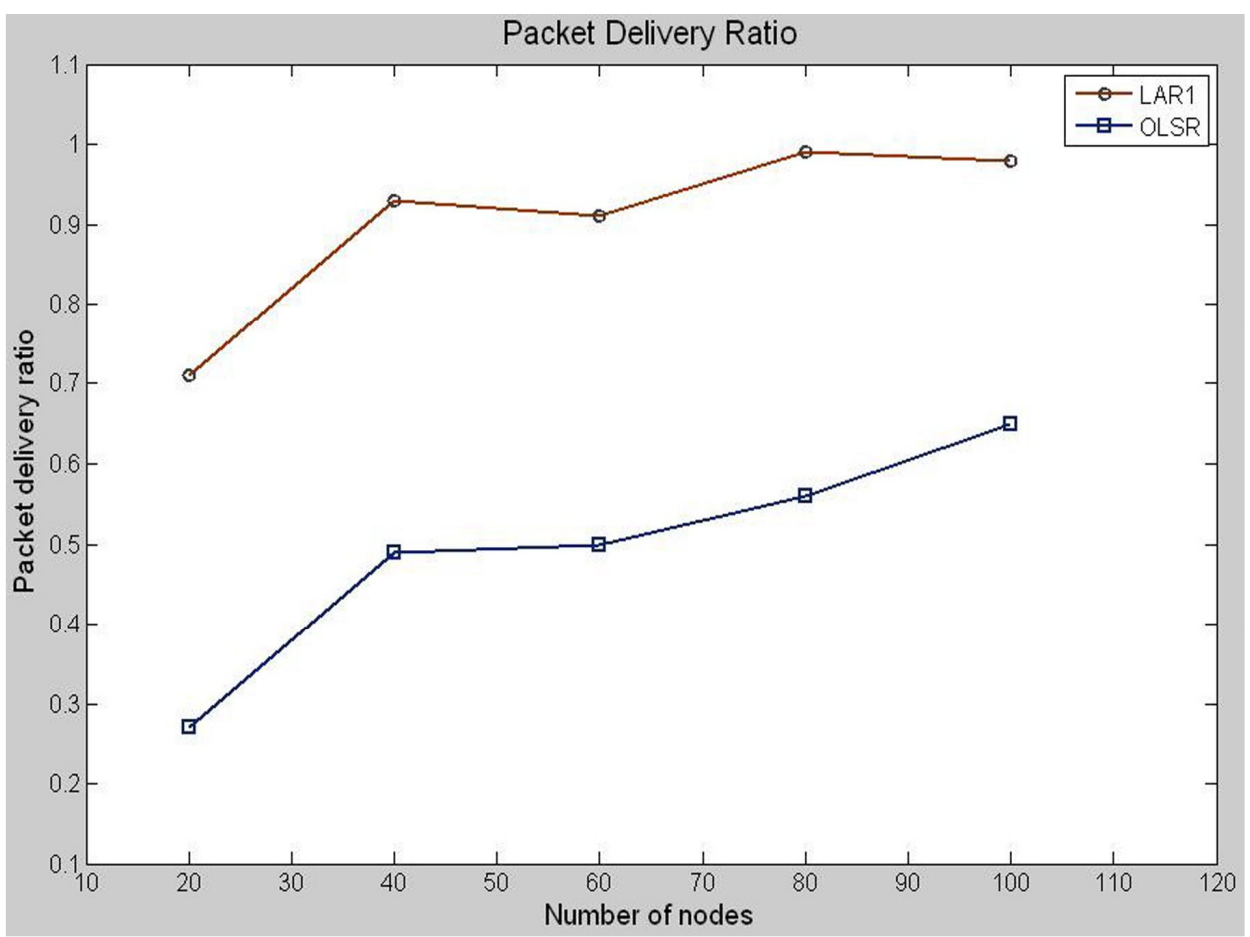

Figure 7. Packet delivery ratio for pause time $30 \mathrm{sec}$ 


\subsection{Throughput}

The throughput is defined as the total amount of data a receiver receives from the sender divided by the time it takes for the receiver to get the last packet. The throughput is measured in bits per second (bit/s or bps) [12]. The throughput is shown in figure 8 and figure 9 for scenario A and scenario B respectively. According to our simulation results, LAR1 shows better performance than OLSR for both scenarios because LAR1 decreases overhead of route discovery by using the location information for mobile host and it can adjust dynamically in case of the change in the network topology. OLSR has worse performance in throughput than LAR1 because most of the nodes can not participate in data transfer as well as it cannot repair route of breakage path.

\subsection{Average Jitter}

Jitter is the variation in the time between packets arriving, caused by network congestion, timing drift, or route changes. Jitter should be small for a routing protocol to perform better [13]. The average jitter is shown in figure 10 and figure 11 for scenario A and scenario B respectively. According to our simulation results, OLSR shows better performance than LAR1 for both scenarios because OLSR is proactive in nature and it uses multipoint relaying technique for selective flooding of control messages to provide optimal routes in terms of number of hops. Initially, when node density is less, jitter is very high in scenario B but it decreases as node density increases.

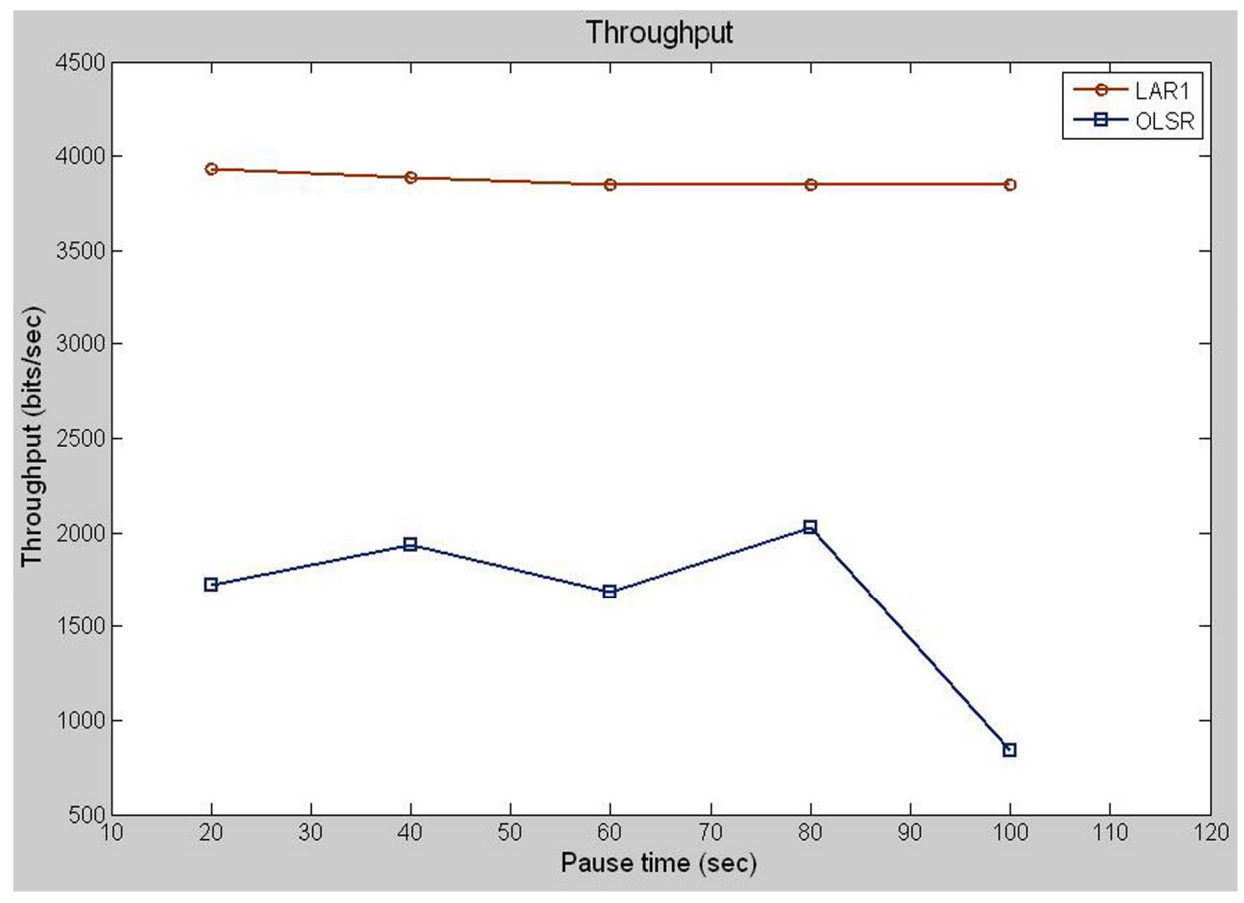

Figure 8. Throughput for 50 nodes 
International Journal of Computer Networks \& Communications (IJCNC) Vol.3, No.6, November 2011

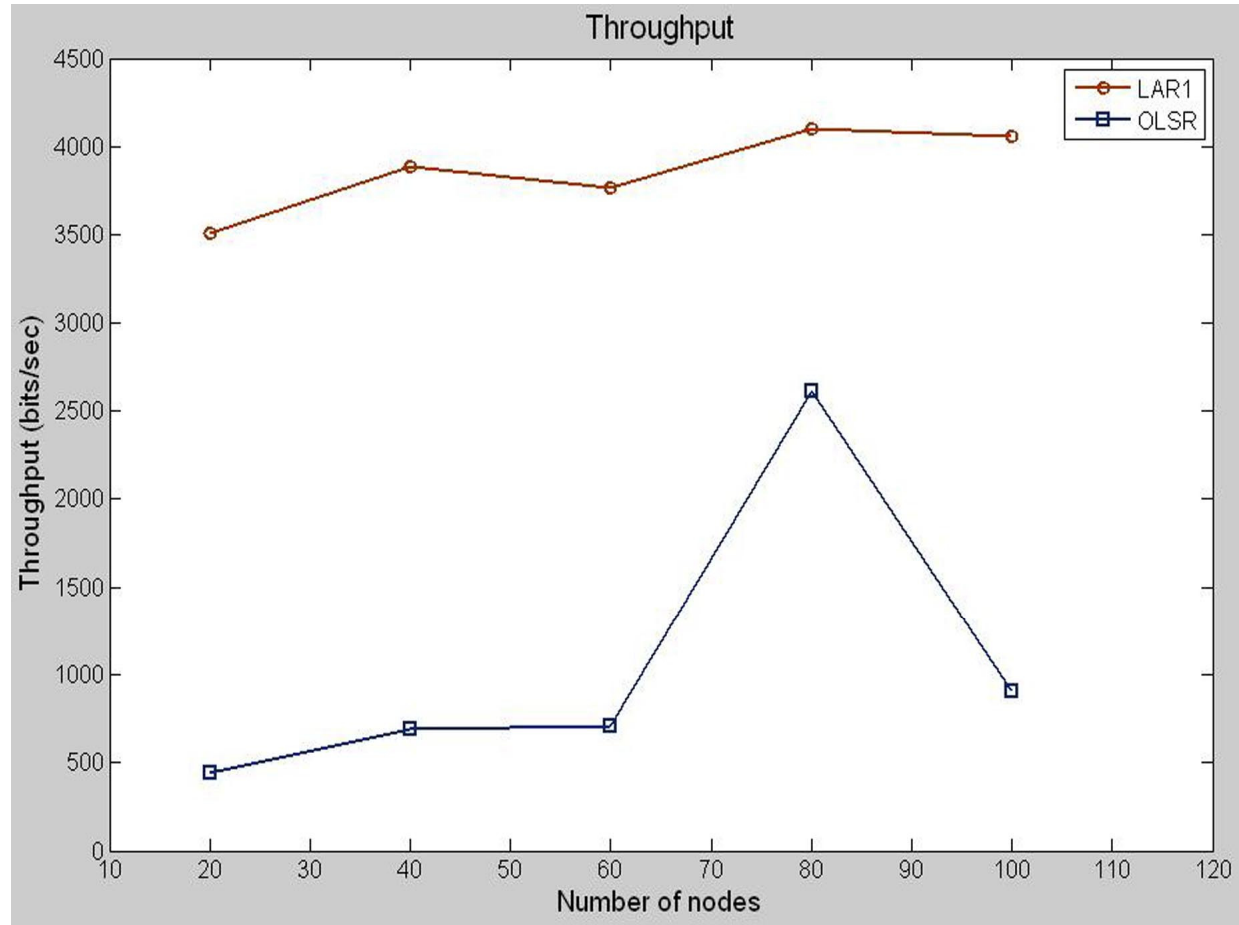

Figure 9. Throughput for pause time $30 \mathrm{sec}$

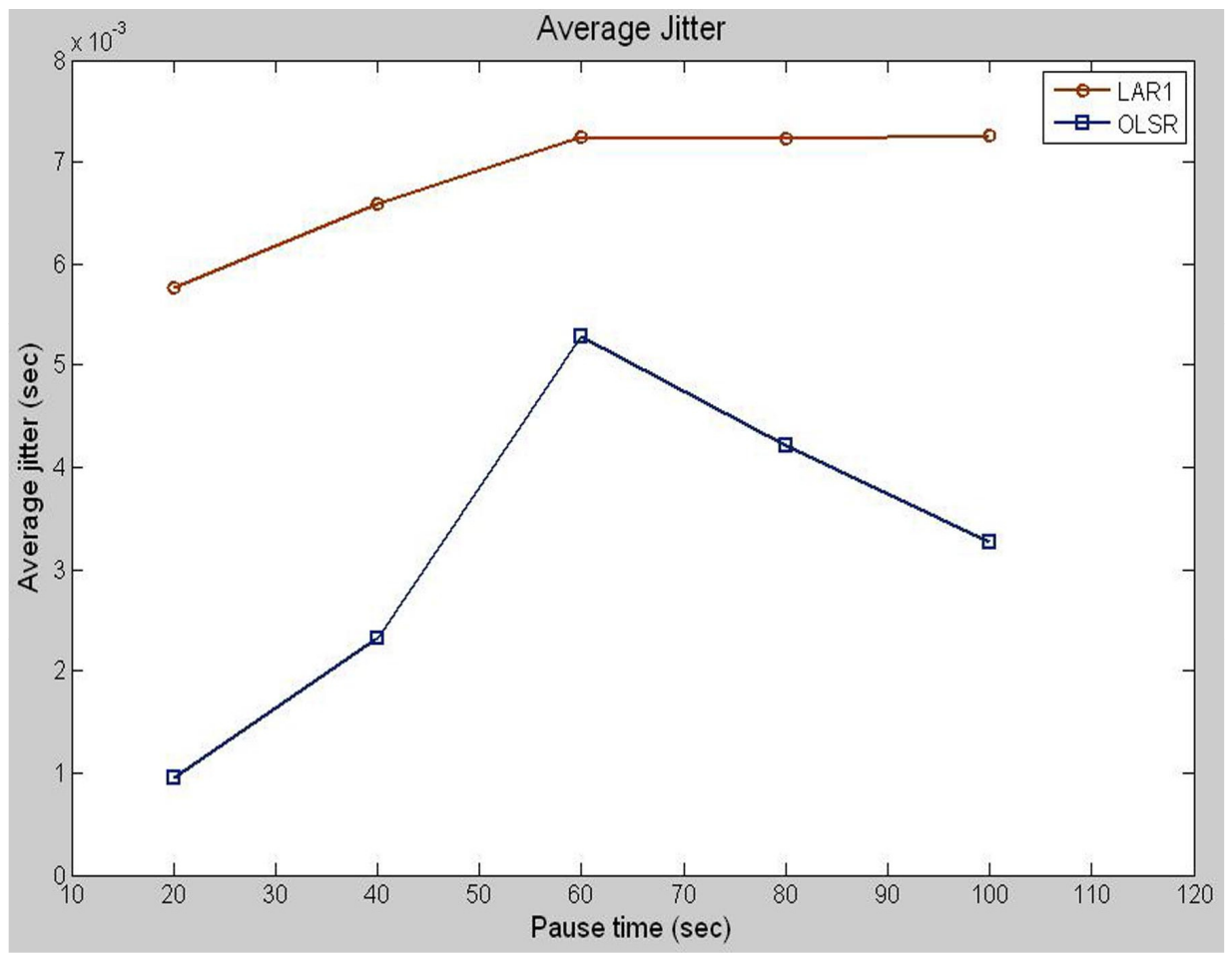

Figure 10. Average Jitter for 50 nodes 
International Journal of Computer Networks \& Communications (IJCNC) Vol.3, No.6, November 2011

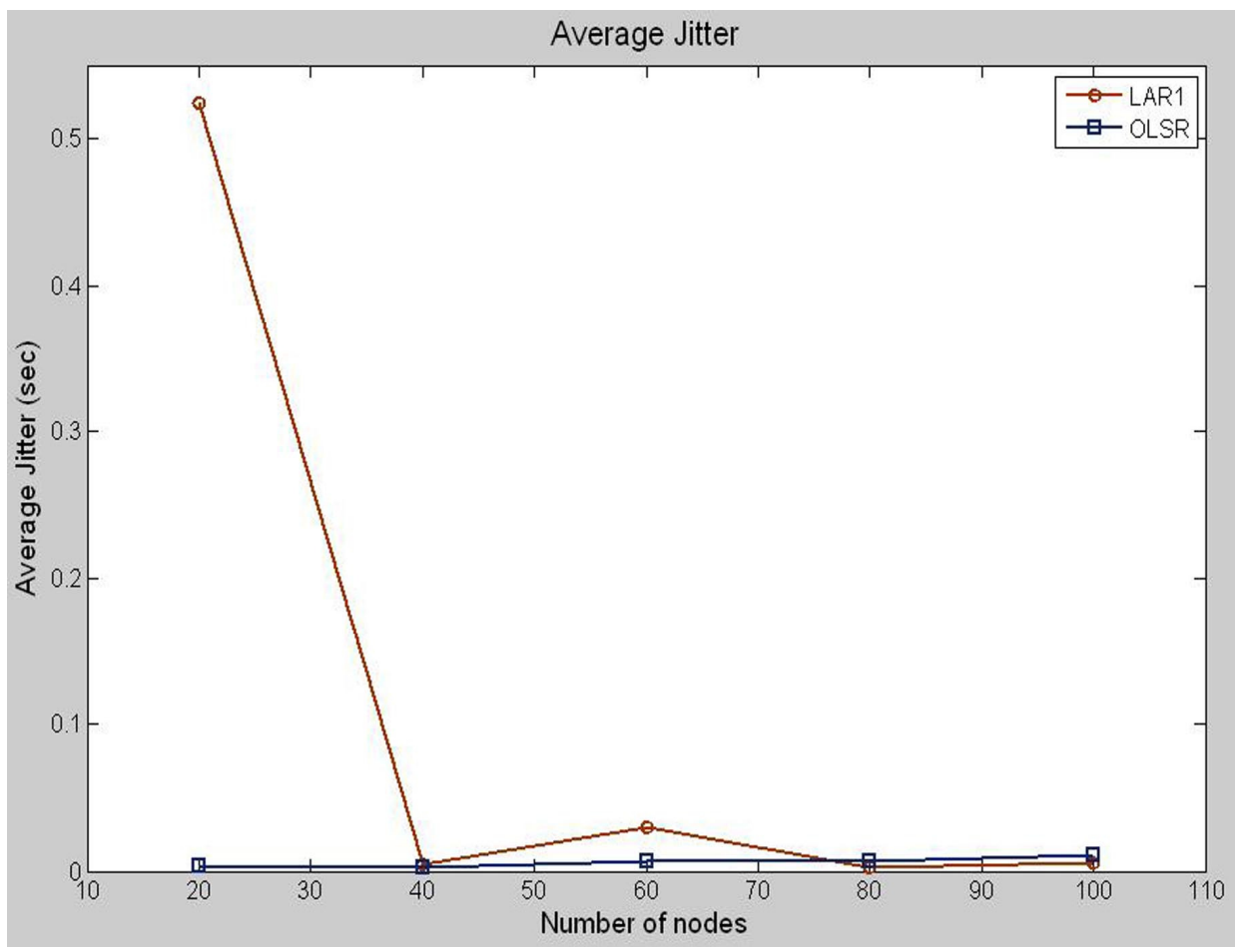

Figure 11. Average Jitter for pause time $30 \mathrm{sec}$

\section{CONCLuSion}

In this paper, a performance of OLSR and LAR1 routing protocol for mobile ad-hoc networks have been evaluated and presented as a function of pause time and number of nodes. We have evaluated the performance of OLSR and LAR1 routing protocol with respect to four performance metrics such as average end to end delay, packet delivery ratio, throughput and average jitter. For both scenarios, OLSR has shown better performance than LAR1 in terms of average end-to-end delay and average jitter due to its proactive nature and LAR1 shown better performance than OLSR in terms of packet delivery fraction and throughput due to less overhead in route discovery by using location information of mobile nodes. In future, different node placement strategies, more sources, additional metrics such as TTL based average hop count, routing overhead may be used.

\section{REFERENCES}

[1] The QualNet simulator www.scalable-networks.com.

[2] Elizabeth, Royer, Chai-Keong, Toh (1999) "A Review of Current Routing Protocols for Ad Hoc Mobile Wireless Networks," IEEE Personal Communications.

[3] T. Clausen and P. Jacquet (2003) "Optimized Link State Routing Protocol (OLSR)", IETF: The Internet Engineering Taskforce RFC 3626, last accessed on Nov 2010.

[4] Jacquet, P.; Muhlethaler, P.; Clausen, T.; Laouiti, A.; Qayyum, A.; Viennot, L.; (2001) "Optimized Link State Routing Protocol for Ad Hoc Networks," Proceedings of IEEE International Multi Topic Conferenc on Technology for the 21 st Century, (IEEE INMIC 2001), pp62- 68. 
International Journal of Computer Networks \& Communications (IJCNC) Vol.3, No.6, November 2011

[5] Young-Bae Ko and Nitin H. Vaidya (1998) "Location-Aided Routing (LAR) in mobile ad hoc networks," Proceedings of $4^{\text {th }}$ ACM/IEEE International Conference on Mobile Computing and Networking (MOBICOM'98), pp66-75.

[6] David Oliver Jörg; (2003) "Performance Comparison Of MANET Routing Protocols In Different Network Sizes".

[7] Arshad, J; Azad M.A.; (2006) "Performance Evaluation of Secure On-Demand Routing Protocols for Mobile Ad-Hoc Networks," $3^{\text {rd }}$ Annual IEEE Communications Society on Sensor and Ad Hoc Communications and Networks (SECON '06), vol. 3, pp971-975.

[8] Chaudhry, S.R.; Al-Khwildi, A.N.; Casey, Y.K.; Aldelou, H.; Al-Raweshidy, H.S.; (2006) "WiMob Proactive and Reactive Routing Protocol Simulation Comparison," Information and Communication Technologies ( ICTTA '06) , vol.2, pp2730-2735.

[9] Bettstetter, C.; Resta, G.; Santi, P.; (2003) "The node distribution of the random waypoint mobility model for wireless ad hoc networks," IEEE Transactions on Mobile Computing, vol. 2, no. 3, pp257269.

[10] David Oliver Jorg; (2003) "Performance Comparison of MANET Routing Protocols In Different Network Sizes", Computer Science Project, Institute of Computer Science and Applied Mathematics, Computer Networks and Distributed Systems (RVS), University of Berne, Switzerland.

[11] Jorjeta G.Jetcheva and David B. Johson; (2004) "A Performance Comparison of On-Demand Multicast Routing Protocols for Ad Hoc Networks," School of Computer Science, Computer Science Department, Pittsburgh.

[12] U. T. Nguyen and X. Xiong; (2005) "Rate-adaptive Multicast in Mobile Ad-hoc Networks," IEEE International Conference on Ad hocand Mobile Computing, Networking and Communications (WiMob 2005), Monreal, Canada.

[13] Talooki, V. N.; Ziarati, K.; (2006) "Performance Comparison of Routing Protocols For Mobile Ad Hoc Networks," Asia-Pacific Conferrence on Communicatios (APCC '06), pp1-5.

[14] Ashish K. Maurya, Dinesh Singh, Anil K. Sarje;(2011) "Performance Comparison of DSR, OLSR and FSR Routing Protocols in MANET using Random Waypoint Mobility Model," IEEE International Conference on Network Communication and Computer (ICNCC-2011), New Delhi, India.

[15] Dinesh Singh, Ashish K. Maurya, Anil K. Sarje;(2011) “Comparative Performance Analysis of LANMAR, LAR1, DYMO and ZRP Routing Protocols in MANET using Random Waypoint Mobility Model," 3rd IEEE International Conference on Electronics Computer Technology (ICECT 2011), Kanyakumari, India. 